\title{
Correction: COVID-19 Contact Tracing Apps: A Technologic Tower of Babel and the Gap for International Pandemic Control
}

\author{
Li Du ${ }^{1}$, MBBS, LLB, PhD; Vera Lúcia Raposo ${ }^{1,2}$, BA, LLB, LLM, PhD; Meng Wang ${ }^{1}$, LLB, LLM
}

${ }^{1}$ Faculty of Law, University of Macau, Macau, SAR, China

${ }^{2}$ Faculty of Law, University of Coimbra, Coimbra, Portugal

Corresponding Author:

Li Du, MBBS, LLB, PhD

Faculty of Law

University of Macau

Avenida da Universidade, Taipa

Macau, SAR, 999078

China

Phone: 85388224733

Email: stephendu@um.edu.mo

\section{Related Article:}

Correction of: https://mhealth.jmir.org/2020/11/e23194/

(JMIR Mhealth Uhealth 2020;8(12):e23194) doi: 10.2196/26239

In "COVID-19 Contact Tracing Apps: A Technologic Tower of Babel and the Gap for International Pandemic Control" (JMIR Mhealth Uhealth 2020;8(11):e23194) the authors noted one error.

This article was inadvertently published with the incorrect country code for the phone number of the Corresponding Author. The phone number was originally published as "86 88224733". This has been corrected to "853 88224733".
The correction will appear in the online version of the paper on the JMIR Publications website on December 7, 2020, together with the publication of this correction notice. Because this was made after submission to PubMed, PubMed Central, and other full-text repositories, the corrected article has also been resubmitted to those repositories.

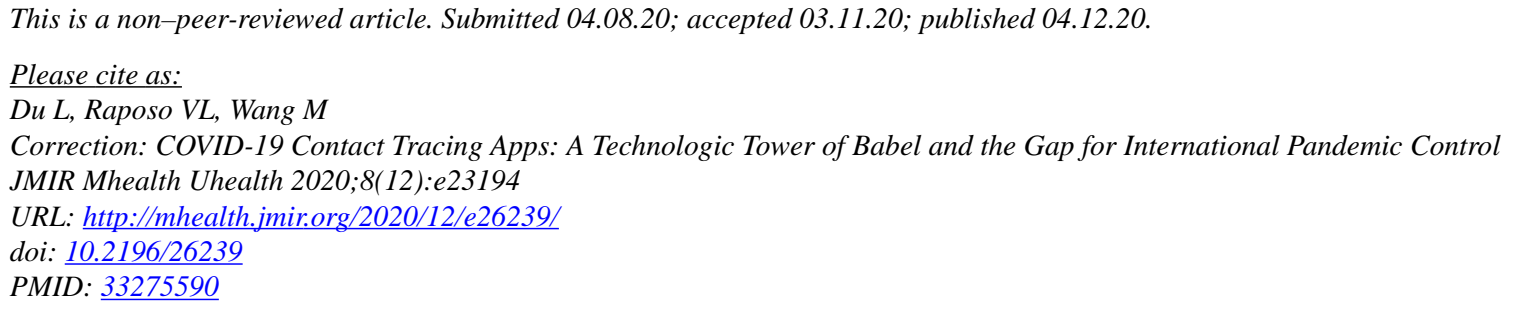

CLi Du, Vera Lúcia Raposo, Meng Wang. Originally published in JMIR mHealth and uHealth (http://mhealth.jmir.org), 04.12.2020. This is an open-access article distributed under the terms of the Creative Commons Attribution License (https://creativecommons.org/licenses/by/4.0/), which permits unrestricted use, distribution, and reproduction in any medium, provided the original work, first published in JMIR mHealth and uHealth, is properly cited. The complete bibliographic information, a link to the original publication on http://mhealth.jmir.org/, as well as this copyright and license information must be included. 